\title{
CANAIS DE MARKETING, VALOR E ESTRUTURAS DE GOVERNANÇA
}

\author{
Ricardo Fasti de Souza \\ Professor do Departamento de Mercadologia da FGV-EAESP. \\ E-mail: fasti@fgusp.br
}

\begin{abstract}
RESUMO
Este artigo discute a contribuição do marketing para a apropriação de fluxos de caixa superiores em transações entre membros do canal de marketing. Propõe-se um modelo em que a capacidade de apropriação de fluxo de caixa pelos membros do canal é resultado da forma como a estrutura de governança transacional é construída em relação às fontes individuais de geração de valor, de poder e do grau de dependência entre os membros.
\end{abstract}

\section{ABSTRACT}

This article discusses the marketing contribution in the appropriation of superior cash flow in transactions between marketing channel members. A model is presented suggesting that the cash flow appropriation capabilities

of the channel member is result of how the transactional governance structure is built regarding the sources of value creation, power and the level of dependency among channel members.

\section{PALAVRAS-CHAVE}

Canais de distribuição, custos de transação, fontes de valor, poder, dependência.

\author{
KEY WORDS
}

Distribution channels, transaction costs, value sources, power, dependence. 


\section{INTRODUÇÃO}

Cresce, atualmente, entre diversos autores (Zajac e Olsen, 1993; Hunt e Morgan, 1995, 1996; Srivastava et al., 1998; Gosh e John, 1999), a preocupação com o impacto das atividades e estratégias de marketing na geração e apropriação de valor para a empresa e seus acionistas. De acordo com Srivastava (1999), existem duas questões centrais e desafiadoras à teoria e à prática mercadológicas: a) a conexão do marketing aos demais processos funcionais da firma e b) os impactos de sua ação sobre o fluxo de caixa da empresa. Adicionalmente, Srivastava (1999, p. 168) observa que, se o marketing contribui para a renovação e o crescimento dos negócios, e para a obtenção e a retenção de consumidores, precisa resultar em fluxos de caixa melhorados - um requisito central para a geração de valor ao acionista.

O processo de obtenção e retenção de consumidores e o impacto na geração de caixa ocorrem por meio da transação, considerada o elemento focal do contato entre dois agentes econômicos ${ }^{1}$ (Dwyer et al., 1987). Esse contato constitui uma díade, ou um par transacional (Achrol et al., 1983), e pode ser do tipo firma-usuário final ou firma-firma.

A Figura 1 descreve o modelo transacional entre uma díade do tipo firma-firma, a menor unidade transacional de um arranjo de canal de marketing. $\mathrm{O}$ valor da transação gerada entre ambas é primariamente de ordem econômica, uma vez que são firmas, e cada uma buscará otimizar sua apropriação de tal valor. Essa capacidade de apropriação do valor transacional deve ser função de uma série de variáveis como o tipo de relacionamento entre as partes, o modo como elas estruturam o ambiente da própria transação e a capacidade individual de criação de valor (Dwyer et al., 1987).

Tornam-se relevantes, por conseguinte, tanto a compreensão das variáveis que influenciam a capacidade de repartição do valor entre os membros de um arranjo de canal de marketing quanto o desenvolvimento de uma medida que aponte essa distribuição.
Assim, este artigo tem dois objetivos: a) discutir o processo de apropriação de valor entre agentes transacionais - membros de um arranjo de canais de marketing - utilizando, como referencial teórico, a economia dos custos de transação (Coase, 1937; Williamson, 1979), a teoria da vantagem competitiva (Day e Wensley, 1988; Petraf, 1993; Day e Nedungandi, 1994; Slater e Narver, 1994) e a teoria

\section{SE O MARKETING CONTRIBUI}

\section{PARA A RENOVAÇÃO E O CRESCIMENTO DOS NEGÓCIOS, ENTÃO, PRECISA TAMBÉM \\ PROMOVER FLUXOS \\ DE CAIXA MELHORADOS.}

de poder e dependência no canal de distribuição (ElAnsary e Stern, 1972; Ouchi, 1979); b) criar uma medida de apuração da repartição do valor entre os membros de um arranjo de canal. Para tanto, será proposto um modelo para o entendimento das forças atuantes em uma negociação - que acabam por determinar o montante de valor apropriado por cada parte na transação e que, em última instância, representa a fração a ser dispensada aos acionistas -, buscando contribuir com uma das questões centrais apontadas por Srivastava (1999): o impacto das estratégias de marketing, especificamente as de canais de marketing, sobre o fluxo de caixa da firma.

\section{FONTES DE GERAÇÃO DE VALOR}

Os ativos de marketing e a geração de valor

De acordo com Srivastava et al. (1998, p. 4), um ativo pode ser definido "amplamente como qualquer atri-

\section{Figura 1 - Modelo típico de uma transação diádica}

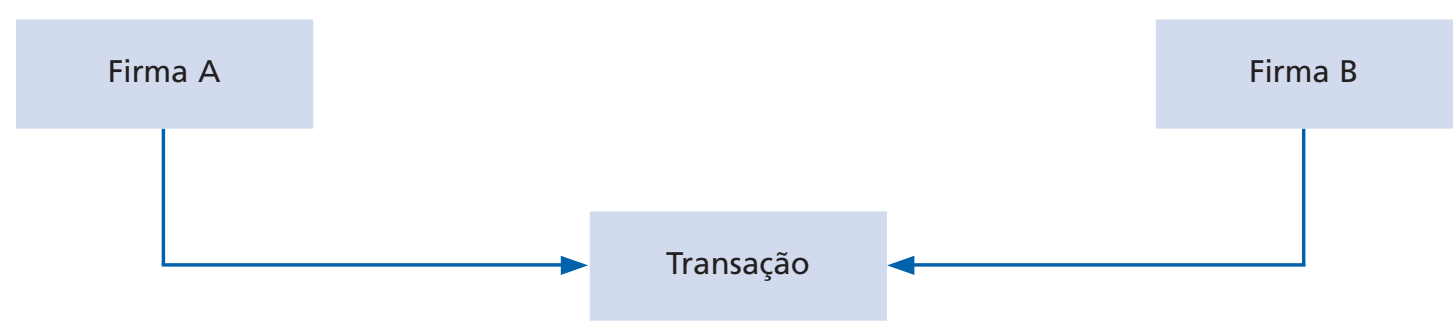


buto físico, organizacional ou humano que permita à firma gerar, e implantar, estratégias que melhorem sua eficiência e eficácia no mercado". Essa definição, ao agregar atributos organizacionais e humanos ao conceito de ativos, possibilita que eles sejam considerados como um contínuo, partindo da tangibilidade e chegando à intangibilidade, de instalações fabris ao conhecimento do comportamento dos consumidores, por exemplo.

\section{A SEGMENTAÇÃO E O}

\section{POSICIONAMENTO CRIAM}

\section{BARREIRAS À MOBILIDADE}

\section{DA DEMANDA PROTEGENDO}

\section{O RETORNO DO INVESTIMENTO.}

Há uma categoria de ativos intangíveis que se origina da interação da empresa com o mercado. São os ativos baseados em mercado, cuja classificação, segundo Srivastava et al. (1998, p. 5), é a seguinte:

a) Relacionais: são ativos intangíveis, resultantes de relacionamentos entre a firma e os agentes que com ela transacionam. O relacionamento constitui-se em um ativo uma vez que pode ser explorado e alavancado para incremento e geração de negócios entre a firma e seus agentes. Incluemse, nessa categoria, os canais de distribuição e os próprios clientes ou consumidores (Hunt e Morgan, 1995).

b) Intelectuais: são ativos compostos pelos tipos de conhecimento desenvolvidos pela firma sobre o ambiente. São formados pela interação da empresa com seu meio ambiente, abrangendo canais e consumidores, e facilitam a criação de mecanismos eficazes de controle, de atendimento a necessidades ou de solução de problemas de clientes e consumidores.

A criação de valor para o consumidor/cliente é alcançada pela obtenção de posições favoráveis como resultado da gestão e da alavancagem de ativos baseados em mercado (Srivastava et al., 1998), ou seja, o objetivo mercadológico de obtenção e retenção de consumidores pela criação de valor concretiza-se por gestão e alavancagem apropriadas dos ativos baseados em mercado.

A alavancagem desses ativos, pela firma, pode ocorrer com os seguintes propósitos (Srivastava et al., 1998; Gosh e John, 1999): a) diminuição de custos pelo conhecimento dos canais e dos consumidores, e pela cons- trução de relacionamentos; b) obtenção de prêmios em preços, já que o patrimônio da marca conduz à percepção de maior valor agregado; c) geração de barreiras competitivas pela construção de lealdade e criação de custos de mudança (Gosh e John, 1999); d) criação de um limite competitivo; e) promoção da possibilidade de extensões de marca e de categorias.

\section{Definição de valor para o acionista}

Srivastava et al. (1998, p. 9) propõem que o valor de qualquer estratégia mercadológica seja definido por critérios de fluxo de caixa, à medida que:

a) acelera os fluxos de caixa;

b) aumenta os níveis do fluxo de caixa;

c) reduz os riscos associados aos fluxos de caixa e, por essa razão, indiretamente, o custo de capital da firma;

d) incrementa o valor residual do negócio.

Vários são os conceitos e medidas que procuram captar as variações do fluxo de caixa (Malta Filho, 1999). Por limitação de espaço, não serão exploradas as diferentes medidas, contudo, para o leitor curioso, sugere-se a leitura de Rappaport (1998).

Utiliza-se, neste artigo, o modelo GVA®, da FGV/ BCG, de avaliação de valor para o acionista. Do conjunto de indicadores propostos pelo GVA®, o que se apresenta mais promissor na captação das variações de caixa sob responsabilidade da função de marketing é o CVA ou Cash Value Added, que se refere ao desempenho de geração de caixa do produto (Malta Filho, 1999, p. 21). Segundo a equação (1), o CVA pode ser definido como:

$$
\mathrm{CVA}=\mathrm{FCL}-\mathrm{K} \cdot \mathrm{d}-\mathrm{K} \cdot \mathrm{CPMC}(1)
$$

Em que:

a) $\mathrm{FCL}=$ fluxo de caixa livre, de natureza operacional em um dado período - no presente estudo, o mês contábil;

b) $\mathrm{K}=$ valor do capital investido;

c) $\mathrm{d}=$ fator de amortização de capital;

d) $\mathrm{CPMC}=$ custo ponderado médio do capital.

O membro K.d da equação (1) corresponde à depreciação econômica ou à parcela que, aplicada em um fundo e capitalizada ao CPMC, gera um montante, ao final da vida útil do ativo, igual ao próprio capital investido (K). Já a parcela K.CPMC é o custo de oportunidade do capital investido.

Se for considerado que K.d e K.CPMC são custos relativos aos recursos emprestados pelos capitalistas (Malta Filho, 1999, p. 7) e que esses custos serão chamados de Custos Econômicos e de Capital (CECA), então, pode-se escrever (1) da seguinte forma: 


$$
\mathrm{CVA}=\mathrm{FCL}-\mathrm{CECA}(2)
$$

Ao considerar-se que o FCL é resultado da subtração da receita bruta de todos os custos, diretos e indiretos, impostos e variações no capital investido, escreve-se (2) como:

$\mathrm{CVA}=($ Receita - Custos Totais $)-$ CECA $(3)$

Se a receita for igual ao preço médio unitário $(\overline{\mathrm{p}})$ do produto, multiplicado por sua quantidade vendida (q), então:

$$
\overline{\mathrm{p}}=\frac{\mathrm{CVA}+\text { Custos Totais }+ \text { CECA }}{\mathrm{q}}
$$

O preço médio praticado deve cobrir os custos totais, econômicos e de capital e ainda gerar um excedente, que, a partir desse momento, será denominado valor por período (Malta Filho, 1999, p. 22), já que o preço médio varia de período a período, de negociação para negociação. Note-se que o conceito derivado de (4) é um análogo do conceito econômico de renda e quase-renda (Klein et al., 1978; Petraf, 1993; Kaufmann e Lafontaine, 1994).

\section{O conceito de renda}

O conceito clássico de renda postula que existem firmas com acesso a fatores superiores e que, por conseguinte, possuem custos médios inferiores aos dos concorrentes (Petraf, 1993). No equilíbrio, demanda e oferta igualam-se, sendo o ponto de equilíbrio médio das firmas dado pela igualdade entre preço de mercado e custo marginal. Aquelas firmas que têm acesso a recursos superiores gozam de lucros superiores sob a forma de renda, uma vez que apresentam custos marginais inferiores aos de equilíbrio do mercado, ou seja, dado um preço de mercado, a diferença de custos entre as firmas que possuem acesso a recursos superiores e as que não o têm é definida como renda. A Figura 2 representa o argumento. A firma (A) está em equilíbrio, pois seu custo marginal iguala-se ao preço de mercado. A firma (B), por ter acesso a recursos superiores, opera ao preço de mercado, mas com custo marginal menor, o que lhe permite a apropriação de um fluxo de renda não acessível a (A).

Há, ainda, o conceito de quase-renda, distinto do conceito de renda econômica. A renda gerada não provém de uma diferença entre o preço de mercado e os custos, outrossim, origina-se do preço de mercado determinado pela característica contextual do fator, por exemplo, singularidade ou heterogeneidade. O fluxo de renda gerado não é resultado da diferença entre o preço de mercado e os custos marginais, mas, sim, da diferença entre os diversos preços de mercados para aplicações alternativas do mesmo fator (Klein et al., 1978). O exemplo a seguir ilustra esse conceito.

Assume-se que um ativo é possuído por uma firma (A) e alugado para outra (B). O valor do aluguel é de $\mathrm{R} \$$ 5 mil por mês, mas (A) sabe que o valor que cobre seus custos, inclusive o de capital, é de R\$ 3 mil. Então, o valor de quase-renda desse ativo é o excesso de seu valor, no caso $\mathrm{R} \$ 2$ mil, sobre seu valor segurado ou seu valor na próxima melhor utilização por outro locador.

Pode-se, assim, definir que o valor para o acionista, por analogia à teoria de renda, é o fluxo de caixa excedente a todos os custos, despesas e investimentos operacionais gerado a partir de uma transação, seja pela utilização de capacidades superiores, seja pela criação de estruturas transacionais específicas. O marketing contribui em ambas as perspectivas, ao transformar as

Figura 2 - Ilustração da criação de renda econômica

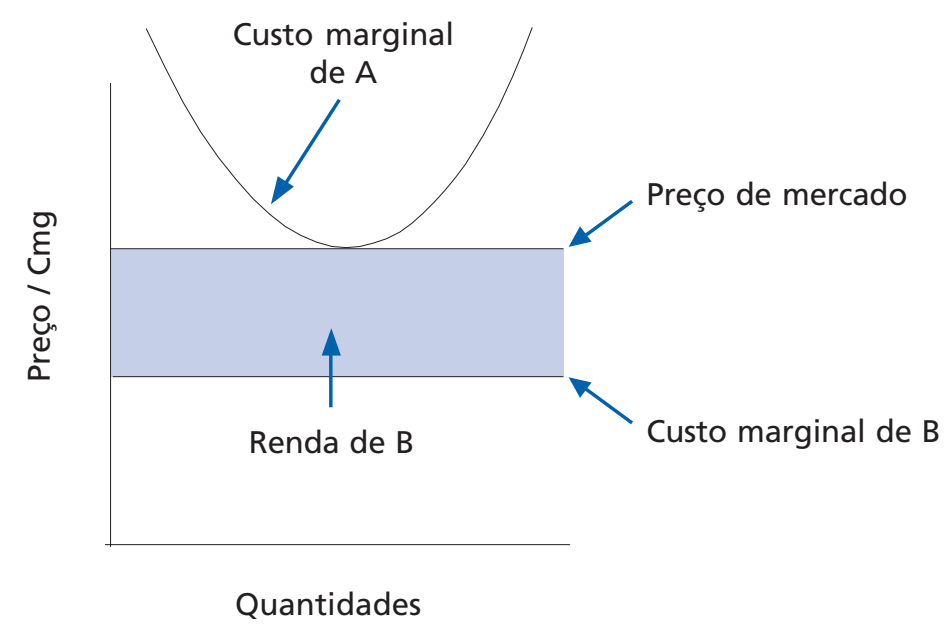


capacidades superiores em valor para o consumidor e/ ou criar estruturas de relacionamento no canal de marketing que permitam o comando de um prêmio sobre a concorrência.

\section{Fontes de geração de valor ao consumidor e ao acionista}

Parece ser evidente que os empreendedores, que se arriscaram a organizar uma firma, procurem resguardar o direito de oferecer (Goldberg, 1976, p. 432), ou seja, busquem criar garantias de volumes de demanda que gerem fluxos capazes de retornar os investimentos, situando o risco dentro de padrões aceitáveis por eles (Chiles e McMackin, 1996). Essas salvaguardas são, geralmente, algum tipo de barreira à mobilidade da demanda, pois, caso o oferente realize investimentos especializados de longo prazo, sua permanência depende da expectativa sobre a disponibilidade futura dessa demanda (Goldberg, 1976, p. 432) e, principalmente, da capacidade de atraí-la e mantê-la. A segmentação, seleção e posicionamento constituem formas de criação de barreiras à mobilidade da demanda ao criarem mecanismos de inibição à busca de alternativas competitivas, entregando valor e limitando, ao mesmo tempo, o ataque competitivo (Kotler, 1988, p. 53-54).

\section{A CAPACIDADE DE DIFERENCIAÇÃO}

\section{DA FIRMA É DECORRENTE DA}

\section{FORMA COMO SEUS RECURSOS}

\section{E ATIVOS SÃO ORGANIZADOS}

\section{POR SEUS GESTORES.}

Ao segmentar o mercado, a firma supõe que existam diferentes curvas de demandas, condicionadas às diferenças entre os segmentos. Ao descobrir critérios que reflitam distintos grupos de consumidores dentro do conjunto original, a firma torna-se capaz de retirar os consumidores de uma única função de demanda agregada e de identificar novas funções, de acordo com as necessidades e problemas dos grupos particulares (Smith, 1956). Ao fazer isso, uma vez que investimentos em pesquisa foram realizados, é esperado que a firma esteja almejando por desempenhos financeiros superiores ao auferidos enquanto o mercado era homogêneo (Hunt e Morgan, 1995), os quais serão obtidos ao se oferecerem produtos e serviços que atendam às expectativas desses segmentos e, portanto, possuam valor para eles.

A diferenciação, por sua vez, constitui-se na tentativa da empresa em mudar ou redirecionar a incli- nação da curva de demanda a favor da oferta de uma firma (Smith, 1956), tornando-a menos sensível ao composto mercadológico do concorrente. A obtenção de posições diferenciadas é conhecida como vantagem competitiva (Ghemawat, 1986; Day e Wensley, 1988; Dierickx e Cool, 1989; Amit e Schoemaker, 1993; Bharadwaj et al., 1993; Petraf, 1993). A firma procura obter desempenhos superiores utilizando sua estrutura de recursos na busca de vantagens sobre a concorrência (Kotler, 1988, p. 53-54). A capacidade de diferenciação da firma, por conseguinte, é dependente de sua aptidão em criar e sustentar vantagens competitivas, que, por sua vez, é decorrente da forma como seus recursos e ativos foram organizados por seus gestores (Collis, 1991; Nelson, 1991; Rumelt, 1991; Day e Nedungandi, 1994; Slater e Narver, 1994; Mehra e Floyd, 1998).

Os recursos e capacidades disponíveis para a estruturação das firmas (Day e Wensley, 1988) podem ser resumidos da seguinte forma:

a) recursos: estoques de fatores possuídos ou controlados pelas firmas. São conhecimentos comercializáveis, ativos físicos e financeiros, capital humano, entre outros.

b) capacidades: habilidades da firma em dispor dos recursos, usualmente combinados com processos organizacionais. Baseiam-se em informações e processos tangíveis e intangíveis específicos à firma, sendo desenvolvidas ao longo do tempo por interações complexas entre os recursos da empresa.

Ativos estratégicos ou fontes de vantagem competitiva e, portanto, de geração de valor, são os recursos e capacidades disponíveis à firma, difíceis de imitar, escassos, passíveis de apropriação e especializados, que garantem a ela vantagem competitiva (Day e Wensley, 1988), criando valor percebido para o consumidor e fluxos de renda para o acionista.

De outra forma, o papel do marketing, sob a ótica da empresa, é administrar as fontes de vantagem competitiva com o propósito de gerar valor para o consumidor, garantindo, assim, fluxos de renda superiores para os acionistas.

\section{ESTRUTURAS DE GOVERNANÇA E APROPRIAÇÃO DE VALOR}

\section{Economia dos custos de \\ transação e estruturas de governança}

Williamson $(1979,1981,1991)$ defende que as firmas sejam estruturas de governança formadas com o propósito de economizar em custos de transação gerados pelo mercado. Esses custos são originados: a) pelo oportunismo, que surge na presença de investi- 
mentos idiossincráticos realizados para a consecução da transação; b) pela freqüência de ocorrência das transações; c) pela assimetria da informação ou incerteza. Adicionalmente, os custos de transação estão relacionados à criação, negociação, acompanhamento e coerção de contratos transacionais (Williamson, 1979; Goldberg, 1976).

Subjacente ao modelo de Williamson (1979, 1981, 1991) está a preocupação em sensibilizar o gestor sobre o potencial de geração de renda oferecido por estruturas de governança, quando os investimentos específicos são altos e surge o ensejo ao comportamento oportunista. Esse é um evento central à estratégia de canais de marketing, visto que um fornecedor, por exemplo, pode tentar evitar o comportamento oportunista do comprador ao criar uma estrutura de governo do canal que iniba a barganha por preço ou por outro tipo de vantagem que eventualmente possa comprometer o fluxo de caixa do fornecedor.

O oportunismo desempenha papel crucial na argumentação sobre a economia dos custos de transação. Ao definir comportamento oportunista como a busca de interesses próprios por meio de artimanhas, Williamson (1979) atraiu para a teoria uma forte crítica, principalmente dos acadêmicos de linha organizacional (Goshal e Moran, 1996). Ao se relaxar o aspecto moral da definição de oportunismo - ou seja, o engano, a artimanha - e confiná-la ao campo transacional, pode redefinir-se oportunismo como a busca personalista do agente econômico por desempenho financeiro superior por meio de exploração das oportunidades de apropriação de valor ou fluxo de caixa, gerado em transações.

Em uma díade (Achrol et al., 1983), se um agente decide investir especificamente para a produção de um bem ou serviço e ao engajar-se em uma troca com outro agente, este procure, oportunistamente, apropriar-se do valor potencial existente na troca, os custos da transação crescem. Aumentam porque o primeiro agente precisa criar salvaguardas contra o comportamento do segundo. Assim, surge a necessidade de constituir uma estrutura de governança específica para garantir que ambas as partes tenham muito a perder caso uma delas se engaje em um comportamento oportunista.

A estrutura de governança é o ambiente em que a integridade comercial e contratual da transação é preservada (Williamson, 1979). Por um lado, essa estrutura garante o direito de servir do oferente e, por outro, assegura ao comprador o direito de ser servido, uma vez que inibe uma eventual redução da oferta por parte do oferente, cuja expectativa seja a de aumentar artificialmente os preços e, com isso, apropriar-se de maior parcela de renda gerada na transação (Goldberg, 1976).
O mercado é uma estrutura de governança para transações que não demandem investimentos específicos para sua realização ${ }^{2}$. Se o oferente investiu especificamente para a produção do bem, então, na presença de concorrência, o comprador pode assumir uma atitude de barganha, sem penalização, caso ela não se concretize. O maior risco é do oferente.

\section{A ESTRATÉGIA DE CANAIS}

\section{DE MARKETING PROCURA CRIAR}

\section{UMA ESTRUTURA DE GOVERNO}

\section{DO CANAL QUE INIBA}

\section{O COMPROMETIMENTO}

\section{DO FLUXO DO CAIXA.}

Quando esse mesmo oferente cria uma estrutura específica para a consecução da mesma transação - os canais de marketing -, há uma redução do impacto da concorrência, diminuindo o poder de barganha do comprador e, por conseguinte, aumentando seus riscos, caso apresente um comportamento oportunista, já que pode estimular o oferente a reduzir ou encerrar o fluxo de fornecimento.

\section{Economia dos custos de transação e canais de marketing}

Os arranjos de canais de marketing são estruturas de governança que, relativamente à sua administração e controle, podem caracterizar-se pela verticalização ou terceirização. Um oferente pode desejar criar um arranjo de canais de marketing em que ele faça os investimentos necessários para abrigar a transação e administre o sistema - é o caso da verticalização. Ao contrário, pode desejar selecionar parceiros que invistam na formação das estruturas de governança (terceiristas) e dividam, com ele, os fluxos de caixa advindos das transações de distribuição. São duas as teorias que sustentam a decisão de fazer (verticalização) ou comprar (terceirização), com relação a canais de marketing. A primeira é a teoria do agente, que será abordada brevemente, e a segunda é a economia dos custos de transação, foco deste artigo.

A teoria do agente (Brickley et al., 1991; Krueger, 1991; Bergen et al., 1992; Lafontaine, 1992; Gupta e Romano, 1998; Combs e Ketchen Jr., 1999) estuda os fenômenos de custos gerados quando um titular concede a um agente o direito de representá-lo na administração dos recursos e capacidades da firma. 
Seja qual for o tipo de titularidade ou agenciamento, o problema que surge a partir dessas combinações está relacionado aos custos de omissão por parte do agente. A omissão caracteriza-se por comportamentos que, de alguma forma, não otimizem a utilização dos recursos ou os destruam por negligência ou imperícia.

A teoria do agente adota uma visão ex ante, na tentativa de evitar ou minimizar custos ex post, utilizando o alinhamento de incentivos antecipados - entendendo incentivos como a política de bonificação anual de um executivo pela consecução dos objetivos ou a comissão de vendedores. Essa teoria constitui-se em uma negociação antecipada aos resultados, de sorte que o agente se sinta estimulado a utilizar bem os recursos, e evita comportamentos oportunistas - custos ex post (Brickley et al., 1991).

A segunda grande vertente que justifica a decisão de integrar ou terceirizar concerne aos custos de transação associados à distribuição dos bens, custos esses relacionados ao comportamento oportunista de um dos participantes da relação de trocas, determinado pelo grau de dependência da outra parte em relação aos investimentos realizados para sua ocorrência, ou seja, quanto mais o agente (A) investiu para a realização da transação, mais dependente ele se encontra para a realização dos fluxos financeiros com vista à obtenção do retorno sobre esse investimento e, portanto, mais exposto ao oportunismo do agente (B), que pouco ou nada investiu para a realização da mesma transação.

Os ativos específicos investidos por (A) demandam retornos cujos riscos estão associados à existência e permanência da demanda, mas, caso essa resolva não se realizar - ocorrência em que (B) se comporta oportunistamente ao não transacionar com (A) ou ao exigir de (A) uma redução significativa de preços -, o perfil de retorno alonga-se para além do ponto no qual os investimentos justificam sua realização. A economia dos custos de transação parte do pressuposto de que os custos ocorrem ex post, devido ao fato de os contratos serem incompletos - conseqüência do fenômeno da racionalidade limitada do gestor (Williamson, 1979; Brickley et al., 1991, p. 7).

Oportunismo e agenciamento são variáveis comportamentais que resultam em custos para os agentes envolvidos na transação. Ao imaginar-se, a partir de Coase (1937), que a firma é uma maneira de organizar transações sob a coordenação do empreendedor e que o mercado também é uma organização de transações, só que sob a coordenação do sistema de preços, pode estender-se o conceito de custos de transação tanto para o ambiente interno da firma no caso, os custos de supervisão e controle que o titular incorre para atalhar o comportamento omisso do agente (Jones e Hill, 1988), o que determina custos transacionais internos majorados - quanto para o ambiente externo, o mercado. Se isso for verdade, então, tanto o custo de agenciamento quanto o de realização de transações entre a firma e seu cliente podem ser classificados sob a categoria genérica de custos transacionais.

Depreende-se, a partir de Williamson (1979), que, em função da estrutura de custos transacionais da empresa, existe um elenco de estruturas de governança com potencial de redução desses custos. Assim, a integração vertical, enquanto arranjo de canal de marketing, traz consigo os custos de agenciamento associados. No extremo oposto, o mercado - também uma estrutura de governança - contém o risco do comportamento oportunista, quando os investimentos realizados por um dos membros da transação ensejam a barganha por parte do outro.

Dessa maneira, conforme a seleção de um arranjo de canal, é possível conhecer, ex ante, os custos incorridos para a consecução da transação internamente à dada estrutura. Em situações competitivas, nas quais a existência de concorrência limita a prática de preços discricionários, a capacidade de apropriação de fluxos de caixa passa a ser condicionada pelo arranjo do canal de marketing selecionado (Williamson, 1979; Zajac e Olsen, 1993; Malta Filho, 1999).

Observou-se, até esse ponto, a relação entre os custos transacionais, a apropriação de fluxos de caixa e o papel da estrutura de canais de marketing. Contudo, conforme Williamson (1979), variáveis de comportamento, como o oportunismo, contribuem fundamentalmente para os custos de transação - veja-se a abordagem da teoria do agente, a assimetria de informação e a freqüência de contato entre os agentes. Desse modo, a abordagem comportamental em canais de marketing é de central importância e mais pertinente ao escopo de marketing para o entendimento da formação dos arranjos de governança dos relacionamentos entre agentes transacionais.

\section{VARIÁVEIS COMPORTAMENTAIS NOS ARRANJOS DE CANAIS DE MARKETING}

\section{Poder no arranjo de canal e apropriação de valor pelos agentes transacionais}

Contesta-se que o único objetivo de uma firma seja a maximização do lucro ou desempenho financeiro superior (Ouchi, 1979), contudo, não se pode negar que, se esse não for o principal objetivo, é, pelo menos, o indicador primordial de desempenho utilizado pelo mercado financeiro para avaliar uma firma e a qualidade de sua administração. Hoje, principalmente, quando o valor de mercado da empresa supera em muito seu valor 
contábil (Gosh e John, 1999), é a capacidade de seus gestores em criar valor que se constitui em uma medida de desempenho fundamental (Malta Filho, 1999).

Não será discutida a importância da geração de valor na hierarquia dos objetivos de uma firma atual, porém será reconhecida sua relevância como medida de capacidade gerencial e de sua força de mercado. Por conseguinte, o entendimento da dinâmica de geração e disputa desse valor é de grande importância para a prática de marketing. Quando se afirma que há uma disputa de geração de valor, parte-se do princípio de ocorrência de transações discretas (Stern e Reve, 1980). Se o produto (A) fosse uma commodity $^{3}$, não seria gerada nenhuma renda (valor) e a receita seria distribuída de acordo com a participação relativa dos custos.

Como há a criação de valor, há um CVA envolvido nessa transação. A pergunta é: qual é o critério de apropriação do CVA para cada um dos membros envolvidos? O CVA representa a criação de valor a partir de ativos intangíveis, os ativos baseados em mercado (Gosh e John, 1999), o que dificulta a criação de um critério objetivo de rateio. Se a determinação da apropriação do valor gerado é de difícil realização, e o valor é a medida de desempenho da firma, torna-se mais evidente a definição de oportunismo apresentada neste artigo, que vem a ser a busca personalista do agente econômico por desempenho financeiro superior, explorando as oportunidades de apropriação de valores gerados em transações. Essa apropriação passa a ser uma fonte potencial de conflito (Varejo, 2000), principalmente pelo exposto anteriormente sobre sua importância estratégica, e o conflito é a origem da criação de uma estrutura de poder (Stern e Reve, 1980).

Poder, segundo os citados autores, é a capacidade que um dos membros do canal tem de influenciar as variáveis do composto mercadológico do outro membro. O composto é o conjunto de ferramentas de marketing utilizado pela firma com seu público-alvo em busca de seus objetivos mercadológicos (Kotler, 1988, p. 92), significando que o membro que exerce poder está interferindo no alcance dos objetivos mercadológicos do outro membro ou até mesmo modificando-os. Se dentre esses objetivos estão a geração e a apropriação de valor para o acionista, então, o membro que exerce o poder pode disputar ou apropriar o valor gerado pelo membro dependente ou, pelo menos, evitar ataques oportunistas.

Atente-se que o agente que detém o poder pode agir de forma oportunista, conforme postulado por Williamson (1979). Para entendimento do propósito deste artigo, o poder passa a ser um fator fundamental para a explicação da apropriação de valor entre os membros do canal. Retomam-se, a seguir, alguns conceitos relacionados a controle, dependência e poder relevan- tes para a argumentação da distribuição de valor entre os membros do arranjo de canal.

Conforme El-Ansary e Robicheaux (1974, p. 2), em seu modelo de controle de canal, as seguintes variáveis definem a estrutura de controle no canal:

a) Autoridade: direito predefinido de afetar o comportamento e que é aceito pelos membros da organização;

b) Poder: habilidade de um membro em influenciar as variáveis de decisão de estratégias de marketing em diferentes níveis de distribuição de um dado canal;

c) Controle: previsão de eventos e alcance de resultados desejados. É obtido por intermédio do poder e autoridade;

d) Liderança: é o exercício de autoridade e poder para alcançar-se controle. Em sistemas interorganizacionais, o esforço de exercer poder e controle é mútuo.

\section{A ESTRUtura DE GOVERNANÇA}

\section{DO CANAL É O AMBIENTE}

EM QUE A INTEGRIDADE

\section{COMERCIAL E CONTRATUAL \\ DA TRANSAÇÃO É PRESERVADA.}

De acordo com Etgar (1976a, 1976b), poder é uma variável resultado, função da dependência e das fontes de poder. El-Ansary e Robicheaux (1974, p. 3) definem dependência da seguinte forma: "A dependência do ator $\mathrm{P}$ sobre o ator $\mathrm{O}$ é (1) diretamente proporcional ao investimento motivacional de $\mathrm{P}$ em objetivos mediados por $\mathrm{O}$ (resultado) e (2) inversamente proporcional à disponibilidade desses objetivos a $\mathrm{P}$, fora da relação O-P (tolerância)."

Os agentes aceitam um aumento de controle se os ganhos percebidos crescem com isso. A tolerância, por sua vez, é diretamente associada à lucratividade. Dessa maneira, a função de resultados é técnica e a de tolerância, comportamental (El-Ansary e Robicheaux, 1974, p. 4).

$\mathrm{O}$ argumento anterior é relevante para justificar as estruturas de governança à medida que os resultados relacionados à apropriação e à criação de valor - função resultado e função tolerância - associam-se ao arranjo de controle (a própria estrutura do canal).

Se assim for, os objetivos fora da relação O-P podem representar opções competitivas, o que reforça a idéia de que o grau de concorrência afeta a dependência, ou seja, quanto menos dependente, mais oportunista um membro pode ser quando o outro realiza investimentos específicos no arranjo. Contudo, se exis- 
tem opções fora do arranjo para ambos, então não é racional que haja o engajamento em comportamentos oportunistas dada a independência de ambos.

$O$ poder de um membro baseia-se nas fontes de poder disponíveis, classificadas em duas categorias segundo Lusch e Brown (1982, p. 319):

a) fontes de poder econômicas: recompensa, coerção e legitimação legal;

b) fontes de poder não econômicas: informação, legitimação tradicional, conhecimento e referência.

A conseqüência do exercício de fontes de poder sobre o controle é que um incentivo direto (fontes econômicas) envolve influência, conduzindo a um controle direto do resultado, enquanto um incentivo indireto (fontes não econômicas) representa influência, levando a um controle indireto do resultado.

\section{O MODELO DE APROPRIAÇÃO DE VALOR}

A apropriação dos fluxos de caixa gerados em uma transação refere-se à capacidade desenvolvida por um membro de preservar seu preço médio planejado ao engajar-se nela. O preço médio é sugerido como o indicador mais adequado para a avaliação da capacidade de apropriação de valor conforme demonstrado na equação (4), uma vez que o valor para o acionista, gerado a partir de um produto, é o resíduo de caixa, resultado da diferença entre o preço e os custos totais. Assim, se o preço médio realizado for menor do que o planejado, a firma (A), que ofereceu o bem, perdeu uma fração $m$ de seu valor planejado para aquela transação, enquanto a firma (B), que comprou o bem, apropriouse da fração $m$ na forma de desconto - o que representa uma redução do custo de aquisição e incrementa a percepção de valor recebido. Dessa maneira, qualquer tipo de desconto não planejado, seja na forma monetária, seja não monetária, representa, para um agente, redução de valor para o acionista e aumento do valor recebido para o outro. O resumo dessas conclusões relativas à apropriação de valor para o acionista é discriminado, a seguir, sob a forma de proposições.

Supondo-se a firma (A) como a oferente e a (B) como a demandante, dessa forma, em uma transação:

a) $\operatorname{Se} \overline{\mathrm{p}}_{\mathrm{r}}<\overline{\mathrm{p}}_{\mathrm{pa}}$, então, (B) apropriou-se do valor esperado por $(\mathrm{A})$, na proporção da redução de preço em relação ao CVA (métrica de apuração de valor) planejado.

b) Se $\overline{\mathrm{p}}_{\mathrm{r}}=\overline{\mathrm{p}}_{\mathrm{pa}}$, então, (A) apropriou-se do valor planejado, e (B) recebeu o valor desejado.

c) Se $\overline{\mathrm{p}}_{\mathrm{r}}>\overline{\mathrm{p}}_{\mathrm{pb}}$, então, (A) apropriou-se do valor que (B) esperava realizar na transação.

Em que $\overline{\mathrm{p}}_{\mathrm{pa}}$ é o preço planejado pela firma (A), $\overline{\mathrm{p}}_{\mathrm{pb}}$ é o preço que a firma (B) está disposta a pagar e $\overline{\mathrm{p}}_{\mathrm{r}}$ é o preço realizado na transação.

Como a geração de valor, para o consumidor e o acionista, é uma função das fontes de vantagens competitivas (Day e Wensley, 1988; Petraf, 1993; Srivastava et al., 1998) - representadas por recursos e capacidades acessados pela empresa e possuidores das qualidades necessárias para serem fontes de valor -, o CVA consiste no valor criado pela utilização desses recursos e capacidades, e o indicador de sua integridade e apropriação é o preço médio realizado na transação.

Assim, um modelo que pretenda descrever o processo de apropriação de valor deve considerar as fontes de geração de valor como variáveis relevantes para o estabelecimento do CVA que se materializa no preço praticado.

A partir de outra perspectiva, o preço médio realizado é fruto do engajamento de duas ou mais partes em uma transação. Essa e qualquer transação sempre ocorrem em uma estrutura de governança, seja ela o mercado, seja uma estrutura corporativa, que está sujeita às forças comportamentais atuantes sobre qualquer sistema social. Como em todos os sistemas sociais, seus membros possuem objetivos próprios, nem sempre convergentes. Essa incongruência clama por um sistema de controle e coordenação, cujo resultado é a criação de uma estrutura de poder e dependência.

O poder surge porque um membro, para a obtenção de seus objetivos, necessita influenciar e controlar as variáveis mercadológicas do outro, o que fica claro quando se trata da apropriação de valor. $\mathrm{O}$ argumento é evidente quando uma firma (A), para transacionar com a firma (B), cria uma estrutura de canal de marketing que inibe comportamentos oportunistas e cujos recursos interessem a (B) e não estejam facilmente disponíveis em outras fontes. Ao mesmo tempo, a firma (A) possui mais acesso, tanto a fontes de poder econômico quanto não econômico, devido à sua maior capacidade de diferenciação. Desse modo, temse uma estrutura de dependência de (B) por (A), sujeita a fontes de poder que serão exercidas pelo membro com maior capacidade de diferenciação, no caso, (A).

Se o objetivo de (A) é a criação de valor, então, é fundamental que, na transação, o valor planejado seja realizado. Exige-se que (A) assuma a liderança e procure controlar o comportamento de (B), de sorte a atingir sua meta de CVA. Assim, um segundo conjunto de variáveis determinantes para a apropriação de valor compreende as fontes de poder e o grau de dependência, que estabelecerão o grau de controle do agente sobre o resultado da transação.

A argumentação desenvolvida até o momento considera apenas um membro da transação. Contudo, como a transação toda é diádica, os elementos que agem sobre (A) também agem sobre (B), em uma estrutura simétrica enquanto processo, mas não necessariamente no que se refere à informação e recursos disponíveis. A Figura 3 resume as variáveis que influenciam o re- 
sultado da transação, que guarda em si a distribuição de valor (CVA) entre os membros da díade ou o preço realizado após o processo de negociação.

O preço médio realizado é fruto da capacidade de geração de valor pelo oferente contrastada com a expectativa de valor do demandante, dentro da estrutura de governança criada para abrigar a referida transação. O preço médio é uma variável resultado, dependente da convergência entre as expectativas de geração e obtenção de valor, influenciada pela estrutura de controle e poder, função da dependência entre os membros e exercício de fontes de poder pelo membro que lidera o arranjo.

\section{DISCUSSÃO}

O modelo desenvolvido indica que a definição e a criação de uma estrutura de governo do canal são fundamentais na busca por fluxos de caixa superiores uma vez que se sugere que a capacidade de apropriação deles - ou a contribuição do marketing para esse fim está condicionada a como as fontes geradoras de valor e de diferenciação da firma, e as variáveis comportamentais de poder e dependência são combinadas para a criação de barreiras à mobilidade, garantindo o direito de servir e ser servido de ambos os membros.

A questão da dependência é central, pois a crescen-

\section{Figura 3 - Modelo de análise de apropriação de valor pelos membros do arranjo do canal}

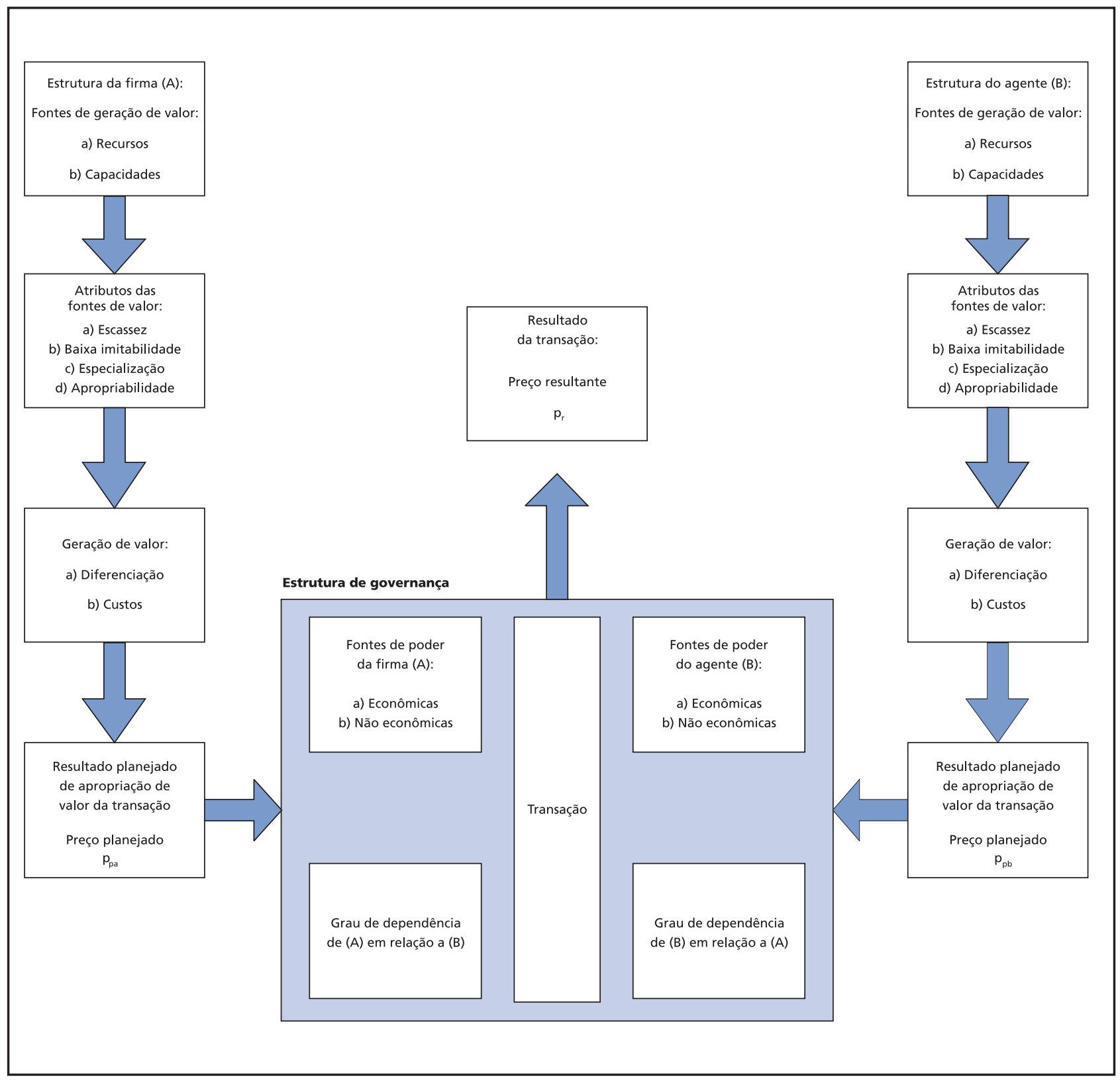


te disputa de preços entre, por exemplo, auto-serviços e fornecedores (Varejo, 2000) parece ocorrer pela menor dependência do auto-serviço em relação ao fornecedor. O auto-serviço, pelo acesso iminente a outras fontes de fornecimento, inclusive a marcas próprias, comporta-se de maneira oportunista em função de sua baixa dependência do fornecedor, que, por sua vez, realizou investimentos maciços, principalmente em marca, para a ocorrência da transação.

A situação descrita fornece indícios de que as fontes de geração de valor para o consumidor não são necessariamente as mesmas de geração de valor para um membro de dado canal de marketing, ou seja, fontes distintas devem ser buscadas e ambientadas em uma estrutura de governança para garantir que as transações sejam perpetuadas entre os membros do canal, de maneira mais relacional ou mais freqüente, conforme o modelo de Williamson (1979), implicando maior interdependência e, por conseguinte, maior mitigação do comportamento oportunista por ambas as partes.

\section{CONCLUSÃO E LIMITAÇÕES}

Atualmente, cresce a preocupação com o impacto das atividades e estratégias de marketing na geração e apropriação de valor para a empresa e seus acionistas. De acordo com Srivastava (1999), existem duas questões centrais e desafiadoras à teoria e à prática mercadológicas: a) a conexão do marketing aos demais processos funcionais da firma e b) os impactos de sua ação sobre o fluxo de caixa da empresa.

Este artigo buscou desenvolver um modelo para o entendimento das forças sob o controle do marketing que atuam sobre a capacidade de apropriação de fluxos de caixa em arranjos de canais de marketing e propor uma medida de apuração da apropriação de valor em uma transação entre membros de um arranjo de canal de marketing.

A dinâmica da transação determina que os agentes engajados em sua consecução procurem extrair, individualmente, valor dela representado pela apropriação do fluxo de caixa gerado nessa transação. Sugeriu-se que a comparação entre o preço médio praticado e o preço médio planejado é o principal indicador sob con- trole do marketing que contribui para a apropriação de fluxos de caixa superiores em arranjos de canais. Explica-se essa proposta a partir do fato de que o preço é uma variável resultado - função do exercício de fontes de geração de valor, de poder e de dependência condicionados ao ambiente de governo da transação, ou seja, à própria estrutura social e comportamental do canal, conforme proposição do modelo.

Um estudo empírico é necessário para se avaliar o impacto das fontes de geração de valor (como relatado, de natureza distinta daquelas utilizadas para criar valor para o consumidor) e de exercício de poder e de dependência na criação de estruturas de canais de marketing com o objetivo de apropriação de fluxos de caixa superiores.

A implicação gerencial pode ser observada nas estratégias de marketing de relacionamento, para as quais se sugere que não somente devam preocupar-se com a entrega de valor para o demandante mas também com a criação de estruturas de governança, a partir da análise simultânea da cadeia de valor do fornecedor e do demandante.

$\mathrm{O}$ modelo pode indicar também que as empresas multidivisionais, nas negociações com o varejo de autoserviço, centralizem todas as categorias e linhas de produto sob uma única administração, alterando o grau de dependência em relação ao comprador. Por exemplo, em uma barganha com o auto-serviço, a divisão de higiene pessoal de um fabricante multidivisional hipotético sente-se compelida a conformar-se à solicitação do comprador em virtude da relação desfavorável de dependência. Contudo, caso o fabricante negocie centralmente todas as suas categorias, a relação de dependência entre as partes tende a tornar-se um pouco mais equilibrada, já que o auto-serviço pode ver-se privado de todas as categorias daquele fabricante, com evidente impacto no faturamento.

O modelo é limitado por ser uma construção de natureza dedutiva, demandando estudos de validação e generalização, entretanto, aparentemente, oferece operadores mensuráveis e que podem servir a um modelo explicativo do papel do marketing na apropriação de valor ao acionista enquanto prática da estratégia de estruturação do canal, e como função da relação de dependência e capacidade de diferenciação dos membros transacionais. $\bigcirc$ NOTAS
1. Para efeito de simplificação, consumidor e cliente
serão utilizados como sinônimos, apesar de haver
distinção formal.
2. A teoria dos custos de transação está centrada nos investimentos necessários para sua realização, e não nos investimentos específicos para a produção do bem ou serviço.
3. Entende-se por commodity a classe de produtos sem diferenciação entre si e que atendem a uma mesma necessidade, um mesmo tipo de problema ou oferecem os mesmos atributos. 


\section{REFERÊNCIAS BIBLIOGRÁFICAS}

ACHROL, R. S., REVE, T. STERN, L. W. The environment of marketing channel dyads: a framework for comparative analysis. Journal of Marketing, v. 47, p. 55-67, Fall 1983.

AMIT, R., SCHOEMAKER, P. J. H. Strategic assets and organizational rent. Strategic Marketing Journal, v. 14, p. 33-46, 1993

BERGEN, M., DUTTA, S., WALKER JR., C. Agency relationships in marketing: a review of the implications and application of agency and related theories. Journal of Marketing, v. 56, p. 1-24, July 1992.

BHARADWAJ, S. G., VADARAJAN, P. R., FAHY, J. Sustainable competitive advantage in service industries: a conceptual model and research propositions. Journal of Marketing, v. 57, p. 83-99, Oct. 1993.

BRICKLEY, J. A., DARK, F. H., WEISBACH, M. S. An agency perspective on franchising. Financial Management, v. 20, n. 2, p. 27-35, Spring 1991.

CHILES, T. H., MCMACKIN, J. F. Integrating variable risk preferences, trust, and transaction cost economics. Academy of Management Review, v. 21, n. 1, p. 73-99, 1996.

COASE, R. H. The nature of the firm. Economica, v. 4, p. 386-405, Nov. 1937.

COLLIS, D. J. A resource-based analysis of global competition: the case of bearings industry. Strategic Marketing Journal, v. 12, p. 49-68, 1991.

COMBS, J. G., KETCHEN JR., D. J. Can capital scarcity help agency theory explain franchising? Revisiting the capital scarcity hypothesis. Academy of Management Journal, v. 42, n. 2, p. 196-207, 1999.

DAY, G. S., NEDUNGANDI, P. Managerial representations of competitive advantage. Journal of Marketing, v. 58, p. 31- 44, Apr. 1994.

DAY, G. S., WENSLEY, R. Assessing advantage: a framework for diagnosing competitive superiority. Journal of Marketing, v. 52, p. 1-20, Apr. 1988.

DICKSON P. R. Toward a general theory of competitive rationality. Journal of Marketing, v. 56, p. 69-83, Jan. 1992.

DIERICKX, I., COOL, K. Asset stock accumulation and sustainability of competitive advantage. Management Science, v. 35, n. 12, Dec. 1989.

DWYER, F. R., SCHURR, P. H., OH, S. Developing buyer-seller relationships. Journal of Marketing, $v$. 51, p. 11-27, Apr. 1987.

EL-ANSARY, A., STERN, L. W. Power measurement in the distribution channel. Journal of Marketing Research, v. IX, p. 47-52, Feb. 1972.

EL-ANSARY, A., ROBICHEAUX, R. A. A theory of channel control: revisited. Journal of Marketing, $v$. 38, p. 2-7, Jan. 1974.

ETGAR, M. Channel domination and countervailing power in the distributive channels. Journal of Marketing Research, v. 13, p. 254-262, Aug. 1976a.
ETGAR, M. Effects of administrative control on efficiency of vertical marketing systems. Journal of Marketing Research, v. 13, p. 12-74, Feb. 1976b.

GHEMAWAT, P. Sustainable advantage. Harvard Business Review, v. 64, n. 5, p. 53-58, Sep./Oct. 1986.

GHOSHAL, S., MORAN, P. Bad for practice: a critique of the transaction cost theory. Academy of Management Review, v. 21, n. 1, p. 13-47, 1996.

GOLDBERG, V. P. Regulation and administered contracts. The Bell Journal of Economics \& Management Sciences, v. 7, p. 426-448, 1976.

GOSH, M., JOHN, G. Governance value analysis and marketing strategy. Journal of Marketing, v. 63, p. 131 145,1999 . Special issue.

GUPTA, S., ROMANO, R. E. Monitoring the principal with multiple agents. Rand Journal of Economics, $v$. 29, n. 2, p. 427-442, Summer 1998.

HUNT, S. D., MORGAN, R. The comparative advantage theory of competition. Journal of Marketing, v. 59, p 1-15, Apr. 1995

HUNT, S. D., MORGAN, R. The resource-advantage theory of competition: dynamics, path dependencies, and evolutionary dimensions. Journal of Marketing, v. 60, p. 107-114, Oct. 1996.

JONES, G. R., HILL, C. W. L. Transaction cost analysis of strategy-structure choice. Strategic Management Journal, v. 9, n. 2, p. 159-132, 1988.

KAUFMANN , P. J., LAFONTAINE, F. Costs of control: the source of economic rents for McDonalds' franchisees. Journal of Law and Economics, v. XXXVII, Oct. 1994.

KEITH, J. E., JACKSON JR., D. W., CROSBY, L. A. Effects of alternative types of influence strategies under different channel dependence structures. Journal of Marketing, v. 54, p. 30-41, July 1990.

KLEIN, B., CRAWFORD, R. G., ALCHIAN, A. A. Vertical integration, appropriable rents, and the competitive contracting process. The Journal of Law and Economics, v. XXI, p. 297-326, Oct. 1978.

KOTLER, P. Marketing management. 6. ed. Englewood Cliffs, NJ : Prentice Hall, 1988. Cap. 1, p. 3.

KRUEGER, A. B. Ownership, agency and wages: an examination of franchising in the fast food industry. Quarterly Journal of Economics, v. 106, n. 1, p. 75101, Feb. 1991.

LAFONTAINE, F. Agency theory and franchising: some empirical results. Rand Journal of Economics, v. 23, n. 2, Summer 1992.

LUSCH, R. F., BROWN, J. R. A modified model of power in the marketing channel. Journal of Marketing Research, v. XIX, p. 313-323, Aug. 1982.

MAITLAND, I., BRYSON, J., VAN DE VEM, A. Sociologists, economists, and opportunism. Academy of Management Review, v. 10, n. 1, p. 59-65, 1985.
MALTA FILHO, A. B. Geração de valor para o acionista: histórico, crítica e sua aplicação na análise de rentabilidade de produtos. Dissertação (Mestrado) Escola de Administração de Empresas de São Paulo, Fundação Getulio Vargas, 1999.

MEHRA, A., FLOYD, S. W. Product market heterogeneity, resource imitability and strategic group formation. Journal of Management, v. 24, n. 4, p. 511-531, 1998

NELSON, R. R. Why do firms differ, and how does it matter? Strategic Management Journal, v. 12, p. 6174, 1991.

OUCHI, W. G. A conceptual framework for the design of organizational control mechanisms. Management Science, v. 52, n. 9, p. 833-848, Sep. 1979.

PETRAF, M. A. The cornerstones of competitive advantage: a resource based view. Strategic Management Journal, v. 14, p. 179-191, 1993.

RAPPAPORT, A. Creating shareholder value. New York : Free Press, 1998.

RUMELT, R. P. How much does industry matter? Strategic Management Journal, v. 12, p. 167-185, 1991.

SLATER, S. F., NARVER, J. C. Does competitive environment moderate market orientationperformance relationship? Journal of Marketing, v. 58, p. 46-55, Jan. 1994.

SMITH, W. Product differentiation and market segmentation as alternative marketing strategies. Journal of Marketing, v. 21, n. 1, July 1956.

SRIVASTAVA, R. K. Marketing, business processes, and shareholder value: an organizationally embedded view of marketing activities and the discipline of marketing. Journal of Marketing, v. 63, p. $168-179,1999$

SRIVASTAVA, R. K., SHERVANI, T. A., FAHEY, L. Market based assets and shareholder value: a framework for analysis. Journal of Marketing, v. 62, p. 2-18, Jan. 1998.

STERN, L. W., REVE, T. Distribution channels as political economies: a framework for comparative analysis. Journal of Marketing, v. 44, p. 52-64, Summer 1980.

VAREJO endurece negociações com a indústria. Gazeta Mercantil, São Paulo, 13 dez. 2000. p. c-1.

WILLIAMSON, O. E. Transaction-cost economics: the governance of contractual relations. Journal of Law and Economics, v. XXII, p. 233-261, Oct. 1979.

WILLIAMSON, O. E. The modern corporation: origins, evolution, attributes. Journal of Economic Literature, v. XIX, p. 1537-1568, Dec. 1981.

WILLIAMSON, O. E. Strategizing, economizing and economic organization. Strategic Management Journal, v. 12, p. 75-94, 1991.

ZAJAC, E. J., OLSEN, C. P. From transaction cost to transactional values analysis: implications for the study of interorganizational strategies. Journal of Management Studies, v. 30, n. 1, Jan. 1993. 